REGARDS

SUR L'ECONOMIE ALLEMANDE

BULLETIN ECONOMIQUE DU CRAC

\section{Regards sur l'économie allemande}

Bulletin économique du CIRAC

$111 \mid 2013$

Varia

\title{
Salaires : les SMIC légaux professionnels en vigueur
}

Isabelle Bourgeois

\section{OpenEdition}

Journals

Édition électronique

URL : http://journals.openedition.org/rea/4631

DOI : 10.4000/rea.4631

ISSN : 1965-0787

Éditeur

CIRAC

Édition imprimée

Date de publication : 1 décembre 2013

Pagination : 35

ISSN : 1156-8992

\section{Référence électronique}

Isabelle Bourgeois, «Salaires : les SMIC légaux professionnels en viqueur », Regards sur l'économie allemande [En ligne], 111 | décembre 2013, mis en ligne le 17 décembre 2013, consulté le 15 septembre 2020. URL : http://journals.openedition.org/rea/4631

Ce document a été généré automatiquement le 15 septembre 2020.

(c) CIRAC 


\title{
Salaires : les SMIC légaux professionnels en vigueur
}

\author{
Isabelle Bourgeois
}

Dans une douzaine de branches ou secteurs, des SMIC légaux ont été adoptés au fil du temps. Le premier secteur à avoir bénéficié d'un tel salaire minimum est le BTP (voir REA 71/2005) et ce, dès 1996, en application de la directive européenne sur le détachement des travailleurs effectué dans le cadre d'une prestation de services. C'est presque toujours la loi allemande sur les travailleurs détachés (ArbeitnehmerEntsendegetz -AEntG), conjuguée à la procédure d'extension des accords conventionnels de branche, qui a été utilisée pour introduire ces SMIC légaux catégoriels ou professionnels. Ces salaires planchers légaux s'appliquent aujourd'hui à quelque 3 millions de salariés. (IB)

Les SMIC professionnels existant en Allemagne à la fin 2013 ( $€$ / heure)

\begin{tabular}{|c|c|c|c|}
\hline Secteurs/métiers & $\begin{array}{l}\text { En vigueur du... } \\
\text { au... }\end{array}$ & $\begin{array}{l}\text { Länder ouest + } \\
\text { Berlin }\end{array}$ & $\begin{array}{l}\text { Nouveaux } \\
\text { Länder }\end{array}$ \\
\hline $\begin{array}{l}\text { Déchets } \\
\text { (175 } 000 \text { salariés) }\end{array}$ & $\begin{array}{l}01 / 02 / 13 \\
30 / 06 / 14\end{array}$ & 8,68 & 8,68 \\
\hline $\begin{array}{l}\text { BTP (activité principale) } \\
\text { ouvriers qualifiés } \\
\text { chauffeurs, conducteurs de } \\
\text { machines } \\
\text { (549000 salariés) }\end{array}$ & $\begin{array}{l}01 / 01 / 14 \\
31 / 12 / 14 \\
01 / 01 / 15 \\
31 / 12 / 15\end{array}$ & $\begin{array}{l}11,10^{\text {a) }} \\
13,95 \quad \text { (Berlin : } \\
13,80)^{\text {b) }} \\
14,20 \quad \text { (Berlin : 14, } \\
05)^{\text {c) }}\end{array}$ & $\begin{array}{l}10,50^{\text {a) }} \\
10,50^{\mathrm{b})} \\
10,75^{\mathrm{c})}\end{array}$ \\
\hline $\begin{array}{l}\text { Extraction minière spécialisée } \\
\text { ouvriers qualifiés } \\
\text { (2 } 500 \text { salariés) }\end{array}$ & $\begin{array}{l}- \\
01 / 07 / 13 \\
31 / 12 / 13\end{array}$ & 12,60 & 11,25 \\
\hline
\end{tabular}




\begin{tabular}{|c|c|c|c|}
\hline $\begin{array}{l}\text { Formation profession. initiale/ } \\
\text { continue } \\
(30000 \text { salariés })\end{array}$ & $\begin{array}{l}01 / 01 / 14 \\
31 / 12 / 14\end{array}$ & 13,00 & 11,65 \\
\hline $\begin{array}{l}\text { Couvreurs } \\
\text { (71 } 600 \text { salariés) }\end{array}$ & $\begin{array}{l}01 / 01 / 13 \\
31 / 12 / 13\end{array}$ & 11,20 & 11,20 \\
\hline $\begin{array}{l}\text { Electriciens (installation) } \\
\text { (295700 salariés) }\end{array}$ & $\begin{array}{l}01 / 01 / 13 \\
31 / 12 / 13\end{array}$ & 9,90 (Berlin : 8,85) & 8,85 \\
\hline $\begin{array}{l}\text { Entretien BTP } \\
\text { techniciens de surface } \\
\text { entretien des façades } \\
\text { ( } 700000 \text { salariés) }\end{array}$ & $\begin{array}{l}01 / 01 / 13 \\
31 / 12 / 13 \\
01 / 01 / 14 / \\
31 / 12 / 14\end{array}$ & $\begin{array}{l}9,00 \\
9,31 \\
12,33\end{array}$ & $\begin{array}{l}7,56 \\
7,96 \\
10,31\end{array}$ \\
\hline $\begin{array}{l}\text { Montage d'échafaudages } \\
\text { (22 } 900 \text { salariés) }\end{array}$ & $\begin{array}{l}01 / 08 / 13 \\
28 / 02 / 14\end{array}$ & 10,00 & 10,00 \\
\hline $\begin{array}{l}\text { Plâtriers-peintres } \\
\text { non qualifiés } \\
\text { qualifiés } \\
\text { (115 } 400 \text { salariés) }\end{array}$ & $\begin{array}{l}01 / 05 / 13 \\
30 / 04 / 14\end{array}$ & $\begin{array}{l}9,90 \\
12,15\end{array}$ & $\begin{array}{l}9,90 \\
9,90\end{array}$ \\
\hline $\begin{array}{l}\text { Services à la personne/santé } \\
\text { (800000 salariés) }\end{array}$ & $\begin{array}{l}01 / 07 / 13 \\
31 / 12 / 14\end{array}$ & 9,00 & 8,00 \\
\hline $\begin{array}{l}\text { Sécurité } \\
\text { (170 } 000 \text { salariés) }\end{array}$ & $\begin{array}{l}01 / 01 / 13 \\
31 / 12 / 13 \\
01 / 10 / 13 \\
30 / 04 / 14\end{array}$ & $\begin{array}{l}7,50 \text { à } 8,90^{d)} \\
11,00\end{array}$ & $\begin{array}{l}7,50 \\
10,13\end{array}$ \\
\hline $\begin{array}{l}\text { Tailleurs de pierre et sculpteurs } \\
\text { (13 } 100 \text { salariés) }\end{array}$ & $\begin{array}{l}01 / 05 / 14 \\
30 / 04 / 15\end{array}$ & 11,25 & 10,66 \\
\hline $\begin{array}{l}\text { Services professionnels de } \\
\text { blanchisserie } \\
\text { (34000 salariés) }\end{array}$ & $\begin{array}{l}\text { Jusqu'au } 31 / 03 / 13 \\
\text { e) }\end{array}$ & 8,00 (Berlin : 7,00) & 7,00 \\
\hline Intérim & $\begin{array}{l}01 / 11 / 12 \\
31 / 10 / 13\end{array}$ & $8,19\left(\right.$ Berlin : 7,50) ${ }^{f)}$ & $7,50^{\mathrm{fl}}$ \\
\hline
\end{tabular}

Source des données : Destatis (salaires, durée des accords ; état au 01/11/2013) et WSI-Tarifarchiv (nombre de salariés concernés ; état : décembre 2013). a) année 2013 : respectivement 11,05€ et 10,25€; b) année 2013 : respectivement 13,70 € (Berlin : 13,55€) et 10,25€; c) pas de salaire distinct avant 2015 ; d) différenciation régionale (Bade-Wurtemberg : 8,90€; Bavière : 8,42 $€$; Rhénanie du Nord-Westphalie : 8,23 €; Hesse : 7,76 €, Basse-Saxe, Brême, Hambourg, Berlin, Rhénanie-Palatinat, Sarre et Schleswig-Holstein : 7,50 €) ; e) actuellement pas de SMIC ; f) procédure d'extension en cours pour 2014 (salaires prévus : 8,50 € à l'ouest et 7,86 € à l'est, Berlin inclus. 
INDEX

Mots-clés : salaire, salaire minimum, politique de l'emploi, politique sociale, marché du travail, conditions de travail 